\title{
The Efficient Market Hypothesis and Identification in Structural VARs
}

\author{
Lucio Sarno and Daniel L. Thornton
}

ra or a variety of reasons economists have long been interested in measuring the economy's response to exogenous shocks. The shocks are thought to result, for example, from specific unexpected policy actions, sources that are exogenous to the domestic economy (such as an oil price shock), or sudden changes in technology. The economic structure (or data-generating process) that determines any economic outcome must be inferred from the observed data, and a structural interpretation of the data is obtained from economic theory. However, there are alternative economic theories and, consequently, alternative structural interpretations of the same observations. Hence, economists are faced with the very difficult problem of discriminating among these interpretations and, consequently, identifying the specific source of the shock or the economy's response to it.

Before a structural model can be evaluated, it must be identified. A structural model is identified when one can obtain the structural parameters from the estimates of the reduced-form parameters. A model is "just identified" when there is a one-to-one correspondence between the structural parameters and the reduced-form parameters. On the other hand, a model is over-identified if there is more than one set of structural parameters that is consistent with a given set of reduced-form parameters, whereas it is unidentified when there is no way to obtain the structural parameters from the estimated reduced-form parameters. ${ }^{1}$

Generally speaking, there have been two broad approaches to identification, the Cowles Commission (CC) methodology and the so-called structural vector

\footnotetext{
1 When a model is over-identified, there is a set of over-identifying restrictions that can be tested as part of a structural model evaluation.
}

autoregression (SVAR) methodology. ${ }^{2}$ As a consequence of Sims's (1980) critique of the CC methodology, the SVAR methodology has become arguably the most widely used method of structural analysis. Both methodologies assume that the structural economy can be approximated by a linear, dynamic system of structural equations with an additive stochastic structure. In applications of the CC methodology, identification was typically achieved by placing restrictions (typically homogenous, i.e., zero, restrictions) on some of the coefficients of a dynamic structural model of the economy. While it was well understood that identification could be achieved by placing restrictions on the stochastic structure of the model, this was seldom done in practice. $^{3}$

In contrast, in the SVAR methodology (which is attributed to Bernanke, 1986; Blanchard and Watson, 1986; and Sims, 1986) identification is achieved by imposing contemporaneous restrictions on both the structure of the economy and the stochastic structure of the model. ${ }^{4}$ Exclusion restrictions on the structural dynamics - which were frequently imposed in applications of the CC methodologyare never imposed.

The restrictions that the SVAR methodology imposes on the structural shocks have often been

\footnotetext{
2 The Cowles Commission methodology is attributable to various researchers who were in one way or another connected to the Cowles Commission for Research in Economics. For a summary of this methodology, see Koopmans (1949). For an early application of it, see Klein (1950).

3 See Koopmans (1949) for a discussion of variance-covariance restrictions.

4 We note that there are identification schemes that impose no contemporaneous restrictions. This literature includes the work of Blanchard and Quah (1989) and Shapiro and Watson (1988). This methodology is not discussed here. See Keating (1992) for an excellent survey of structural VAR approaches to identification.
}

Lucio Sarno is a professor of finance, Finance Group, Warwick Business School, University of Warwick, and a research affiliate, Centre for Economic Policy Research (CEPR), London. Daniel L. Thornton is a vice president and economic advisor at the Federal Reserve Bank of St. Louis. The authors thank Martin Sola, Hiroshi Fujiki, Oscar Jorda, and Yi Wen for comments. John Zhu provided research assistance.

Federal Reserve Bank of St. Louis Review, January/February 2004, 86(1), pp. 49-60.

(C) 2004, The Federal Reserve Bank of St. Louis. 
criticized (e.g., Bernanke, 1986; Stock and Watson, 2001), and Cooley and LeRoy (1985) have noted that, in the absence of these restrictions, the estimated shocks from the SVAR would be linear combinations of all the structural shocks in the reduced-form VAR. This paper extends and refines Cooley and LeRoy's observation by noting that if the VAR includes one or more efficient market variables (EMVs) variables that reflect all information relevant for their determination - the covariance restrictions that are typically employed in a SVAR identification are inappropriate and may have to be replaced with alternative restrictions. Our paper is close in spirit to those of Wallis (1980) and Pesaran (1981) in the rational-expectations literature; however, we focus on SVARs rather than on more general structural rational-expectations models.

Strictly speaking, our analysis applies only to VARs that include variables that are efficient in the strong form of the efficient market hypothesis (EMH). We argue, however, that our analysis is likely to have implications for VARs that include variables that meet the less stringent requirements of semistrong market efficiency. The potential importance of our critique for applied work is illustrated with a SVAR model that is widely used to identify the effects of monetary policy shocks on the economy.

The paper begins with a brief discussion of the CC and SVAR approaches to identification. We then discuss (i) the EMH and the various forms of market efficiency and (ii) the effect of including an EMV in a SVAR model. The implications of our analysis for applied work are illustrated with a widely used SVAR model.

\section{THE CC AND SVAR METHODS OF IDENTIFICATION}

Both the CC and SVAR methods of identification assume that the economy can be approximated by a general linear structural model of the economy of the form

$$
A Y_{t}=B Y_{t-1}+D v_{t},
$$

where $Y_{t}$ is an $\mathrm{N} \times 1$ vector of endogenous variables and $v_{t}$ is a vector of i.i.d. structural shocks, with mean zero and a constant covariance matrix. ${ }^{5}$ Bernanke

\footnotetext{
5 The first-order autoregressive structure is used because any higherorder autoregressive process can be written as a first-order process. For presentation purposes, however, we will assume that the model is strictly first order.
}

(1986, p. 52) notes that these shocks are "primitive" exogenous forces, not directly observed by the econometrician, which "buffet the system and cause oscillations." He notes that "because these shocks are primitive, i.e., they do not have a common cause, it is natural to treat them as approximately uncorrelated." Hence, it is reasonable to assume that $E v_{t} v_{t}^{\prime}=\Lambda$, where $\Lambda$ is a diagonal matrix. This noncontroversial assumption is common to both the CC and SVAR approaches.

The reduced-form of the structural model (i.e., what economists observe) is given by

$$
Y_{t}=A^{-1} B Y_{t-1}+A^{-1} D v_{t}
$$

or

$$
Y_{t}=\Gamma Y_{t-1}+u_{t}
$$

where $\Gamma=A^{-1} B$ and $u_{t}=A^{-1} D v_{t}$.

The economic model is (exactly) identified when it is possible to obtain estimates of the structural parameters (i.e., the elements of $A, B, D$, and $\Lambda$ from the reduced-form parameters) and vice versa (i.e., when there is a one-to-one correspondence between the structural and reduced-form parameters). Identification is achieved by placing restrictions on $A, B$, and $D .6$

In the $\mathrm{CC}$ methodology, identification was typically achieved by imposing restrictions on $A$ and $B$. While it was widely understood that identification could be achieved by imposing restrictions on $D$ or $\Lambda$, such restrictions were seldom imposed in practice. There are $\mathrm{N}^{2}$ unique elements of $\Gamma=A^{-1} B$, but $\mathrm{N}^{2}$ elements in each of $A$ and $B$. Hence, the necessary (order) condition for (exact) identification using the CC methodology is that there are as many zero elements (in the case of homogenous restrictions) in $B$ as there are non-zero elements in $A$. That is, there must be a total of $\mathrm{N}^{2}$ restrictions imposed on $A$ and $B$-the fewer the restrictions imposed on $A$, the more restrictions must be imposed on $B$. If these restrictions are linearly independent (the rank condition for identification), it is possible to go from the reduced-form parameters to the structural parameters and vice versa.

In response to Sims's (1980) claim that the restrictions placed on $B$ were "incredible," the SVAR literature has taken a different approach to identification. No restrictions are placed on $B$. Instead, identification is achieved by placing restrictions on

\footnotetext{
6 Restrictions can also be imposed on $\Lambda$. For example, one might assume that the variance of one structural shock is some multiple of another This possibility is ignored for ease of presentation.
} 
the elements of $A$ and $D$. To see how the model is identified in the SVAR literature, note that $E u_{t} u_{t}{ }^{\prime}=$ $A^{-1} D \Lambda D^{\prime} A^{\prime-1}=\Sigma$, where $\Sigma$ is a real symmetric matrix of rank N. An estimate of $\Sigma$ is obtained by estimating the reduced-form model, i.e.,

$$
\sum_{t=1}^{T} E \hat{u}_{t} \hat{u}_{t}^{\prime}=\hat{\Sigma},
$$

where $\hat{u}_{t}$ is the vector of residuals obtained by estimating equation (3). There are at most $\mathrm{N}(\mathrm{N}+1) / 2$ unique, non-zero elements of $\hat{\Sigma}$. In contrast, there are $\mathrm{N}^{2}$ parameters in $A$, $\mathrm{N}$ elements in $\Lambda$, and $\mathrm{N}^{2}$ elements in $D$. Consequently, there are $2 \mathrm{~N}^{2}+\mathrm{N}$ structural parameters, so that $\left(3 \mathrm{~N}^{2}+\mathrm{N}\right) / 2$ restrictions are needed to satisfy the necessary (order) conditions for identification. Hence, identification can be achieved by imposing $\left(3 \mathrm{~N}^{2}+\mathrm{N}\right) / 2$ restrictions on the $2 \mathrm{~N}^{2}$ elements of $A$ and $D$.

It is frequently assumed in the SVAR literature that $D=I$. With this assumption, there are only $\left(\mathrm{N}^{2}+\mathrm{N}\right) / 2$ restrictions that need to be imposed on $A$. $\mathrm{N}$ of these restrictions can be obtained by assuming that the diagonal elements of $A$ are equal to unity (these are normalization restrictions), which leaves $\mathrm{N}(\mathrm{N}-1) / 2$ required restrictions. ${ }^{7}$ In the case of recursive structural VARs (RSVARs), these restrictions come from assuming that $A$ is lower triangular. 8

\section{THE EMH}

The assumption that SVAR models impose on $A$ and $D$ to achieve identification may not hold if the VAR includes one or more EMVs. To see why, it is useful to briefly discuss the EMH (Samuelson, 1965; and Campbell, Lo, and MacKinlay, 1997). Malkiel (1992, p. 739) states that a "market is said to be efficient with respect to an information set, $\phi$, if security prices would be unaffected by revealing that information to all participants." The degree of market efficiency is usually categorized by the nature of the information set. Markets are said to be efficient in the weak form if the information set only includes the history of prices or returns. For the semi-strong form of market efficiency, the information set is all

\footnotetext{
${ }^{7}$ Even in cases where $D \neq I$, there is a one-to-one correspondence between the structural shocks and the variables in the VAR (e.g., Bernanke, 1986). This is a consequence of the requirement that $D$ must be $\mathrm{N} \times \mathrm{N}$.

8 This is often referred to as a Wold causal chain in honor of Herman Wold, who advocated the theoretical desirability of recursive models in economics, e.g., Wold (1954). In the case of non-recursive structural VARs, the necessary condition for identification is usually achieved by imposing $\mathrm{N}(\mathrm{N}-1) / 2$ homogenous (or in some cases, non-homogenous) restrictions that are rationalized on the basis of economic theory.
}

publicly available information. When market prices reflect the information known to any market participant, they are said to be efficient in the strong form. ${ }^{9}$

Market efficiency is also characterized by the speed with which information is reflected in market prices (e.g., Chordia, Roll, and Subrahmanyam, 2002; and Schwert, 2002). A shock that is initially reflected in only one asset price may, over time, be reflected in other asset prices. The faster the information is reflected in other prices, the more efficient the market is said to be. Financial markets are thought to be efficient with respect to publicly announced (or known) information, in that such information is thought to be rapidly, if not immediately, reflected in asset prices (Malkiel, 1992; and Campbell, Lo, and MacKinlay, 1997). It may take longer for information that is not publicly announced to be incorporated in asset prices; however, a shock that initially affects only one asset price may create arbitrage opportunities. As market participants respond to such opportunities, prices of other assets change. Hence, the longer the period of time over which economic data are averaged, the more likely it is that asset prices will reflect information that is and is not publicly announced.

\section{THE EMH AND THE SVAR IDENTIFICATION}

By definition, an EMV responds contemporaneously to all shocks that are relevant for its determination. This means that none of the elements of the row of $A^{-1} D$ corresponding to the EMV are zero. It is not important whether the response of the EMV to structural shocks is due to the form of $A$ or $D$; nevertheless, if the assumptions made about the form of $A$ are such that the rows of $A^{-1}$ corresponding to the EMVs are zero, the elements of the rows of $D$ corresponding to these variables must be non-zero.

To better understand why this is so, consider a simple three-variable structural model of the economy represented by equation (1). We initially assume that no identifying restrictions are imposed, so that

$$
A^{-1}=\left[\begin{array}{lll}
a_{11} & a_{12} & a_{13} \\
a_{21} & a_{22} & a_{23} \\
a_{31} & a_{32} & a_{33}
\end{array}\right],
$$

9 See Malkiel (1992) for details. 


$$
B=\left[\begin{array}{lll}
b_{11} & b_{12} & b_{13} \\
b_{21} & b_{22} & b_{23} \\
b_{31} & b_{32} & b_{33}
\end{array}\right]
$$

and

$$
D=\left[\begin{array}{ccc}
1 & d_{12} & d_{13} \\
d_{21} & 1 & d_{23} \\
d_{31} & d_{32} & 1
\end{array}\right]
$$

The diagonal elements of $D$ are normalized to unity under the assumption that the structural shocks are unique. Now assume that the second variable in the VAR, $Y_{2}$, is an EMV.

For the sake of illustration, assume that $D=I$, so that the reduced-form error is given by

$$
u_{t}=\left[\begin{array}{l}
u_{1, t} \\
u_{2, t} \\
u_{3, t}
\end{array}\right]=\left[\begin{array}{l}
a_{11} v_{1, t}+a_{12} v_{2, t}+a_{13} v_{3, t} \\
a_{21} v_{1, t}+a_{22} v_{2, t}+a_{23} v_{3, t} \\
a_{31} v_{1, t}+a_{32} v_{2, t}+a_{33} v_{3, t}
\end{array}\right],
$$

where $v_{1}, v_{2}$, and $v_{3}$ denote the first, second, and third primitive structural shocks, respectively.

Note that the reduced-form shocks are related to the structural shocks solely by the structure of $A$. While the point made above applies to any SVAR model, for ease of illustration, we assume a RSVAR, i.e., $A$ is assumed to be lower triangular. With this assumption, equation (4) reduces to

$$
u_{t}=\left[\begin{array}{c}
a_{11} v_{1, t} \\
a_{21} v_{1, t}+a_{22} v_{2, t} \\
a_{31} v_{1, t}+a_{32} v_{2, t}+a_{33} v_{3, t}
\end{array}\right]
$$

Under these assumptions, the first shock is reflected only in the first reduced-form residual, the first and second structural shocks are reflected in the second reduced-form residual, and so on and so forth.

Note that equation (5) is incompatible with our assumption that $Y_{2}$ is an EMV because, under the assumptions made about $A$ and $D, Y_{2}$ responds only to the first and second structural shocks. Hence, given the assumptions made about the structure of $A$, the EMH requires alternative assumptions be made about the structure of $D$.

In the case of a RSVAR, one way the model can be made consistent with the EMH is by letting the EMV appear last in the Choleski ordering. The placement of the variables in the ordering in RSVARs is usually based on economic arguments, however. Hence, changing the recursive ordering in a RSVAR is tantamount to making different assumptions about the structure of the economy. Hence, while placing the EMV last in the recursive ordering overcomes the problem we discuss in this paper, it need not be the "correct" solution.

Alternatively, one could maintain the Choleski ordering and relax the assumptions on $D$. In this example this can be achieved by assuming that $d_{23} \neq 0$. In this case, the reduced-form errors would now be given by

$$
u_{t}=\left[\begin{array}{c}
v_{1, t} \\
a_{21} v_{1, t}+v_{2, t}+d_{23} v_{3, t} \\
a_{31} d_{21} v_{1, t}+a_{32} v_{2, t}+\left(a_{32} d_{23}+1\right) v_{3, t}
\end{array}\right] .
$$

$Y_{2, t}$ responds to the third structural shock due to the assumption that $d_{23} \neq 0$. If the model were exactly identified, however, an additional restriction must be imposed on either $A$ or $\Lambda$ (e.g., $\sigma_{v_{i}}^{2}=\sigma_{v_{j}}^{2}$ for some $i$ and $j$ ) to satisfy the necessary conditions for identification.

Note that if there are two or more EMVs in the VAR, placing these variables last in the Choleski ordering will not overcome the problem unless one of the EMVs deviates from the other by an idiosyncratic shock. ${ }^{10}$ If the recursive structure of $A$ is maintained, identification will have to be achieved by imposing additional restrictions on either $A$ or $\Lambda$.

\section{IMPLICATIONS OF THE EMH FOR APPLIED WORK}

How important is our analysis of the EMH for applied work? This is a difficult question to answer for at least two reasons. First, in general, the answer depends on the nature of the variables included in the SVAR and the structural restrictions imposed for identification. Consequently, the importance of including an EMV in the SVAR must be analyzed on a case-by-case basis.

Second, strictly speaking, our analysis holds only if the SVAR includes a variable that is efficient in the strong form of the EMH, and strong-form market efficiency is a stringent condition that is unlikely to be satisfied in the real world. We believe that our critique may apply to SVARs that include financial market variables that are likely to be efficient in the weak form or in the semi-strong form of the EMH, such as stock prices, interest rates, or possibly exchange rates.

\footnotetext{
${ }^{10}$ For example, the expectations hypothesis holds.
} 
Hence, one area of research where we believe that our analysis is likely to apply is the relatively large body of empirical work devoted to identifying the effects of monetary policy shocks using RSVARs. In a large strand of this literature, U.S. monetary policy shocks are identified using time series on a short-term interest rate-most often the effective federal funds rate - at monthly or lower frequencies, using a RSVAR (e.g., Christiano, Eichenbaum, and Evans, 1996, 1999).

While it is perhaps unlikely that short-term interest rates reflect all market information, there is considerable evidence to suggest that they reflect all publicly available information rather quickly. That is, short-term interest rates (and interest rates, more generally) are likely to satisfy the conditions for the semi-strong form of market efficiency. Further, these markets are dominated largely by public information, with private information playing a limited role relative to, for instance, the stock market. Indeed, the evidence suggests interest rates respond quickly to information that market participants believe is important for determining the stance of monetary policy. For example, interest rates responded quickly to unexpected changes in the stock of money during the period when the Fed was implementing monetary policy by targeting $\mathrm{M} 1$ from October 1979 through October 1982 (e.g., Cornell, 1982, 1983; Roley and Walsh, 1985; and Thornton, 1989). There is also a large body of literature showing that interest rates respond rapidly to a variety of macroeconomic information, albeit different information at different times (see Fleming and Remolona, 1997, for a summary of this literature), and respond intra-day to a number of macroeconomic announcements (e.g., Fleming and Remolona, 1999). To the extent that shocks to macroeconomic variables also reflect such information, the identifying restrictions imposed in the RSVAR will be violated.

The longer the period of time over which interest rates are averaged, the more likely it is that all rates will reflect information that was initially reflected in only one rate. That is, it becomes more likely that interest rates will reflect information that is not publicly known. Hence, the covariance restrictions frequently imposed for identification are more problematic the longer the period of time over which interest rates are averaged.

Some analysts might argue that our conclusion that short-term nominal interest rates are likely to satisfy the EMH runs counter to the treatment of short-term rates in many monetary policy analyses, where the short-term interest rate is treated as a choice variable of the central bank. In this case, the short-term rate need not be an EMV because changes in it are made entirely in response to past information. However, if one takes seriously the evidence that interest rate rules are forward looking (e.g., Clarida, Gali, and Gertler, 2000), it is plausible that the short-term interest rate is consistent with the EMH even if it is determined solely by decisions of the central bank. Consequently, regardless of whether the short-term interest rate is determined by the market or determined by the central bank, it seems possible that the interest rate behaves in a manner consistent with the EMH under certain assumptions. ${ }^{11,12}$

To investigate the significance of our critique for applied work, we estimate a seven-variable VAR similar to that estimated by Christiano, Eichenbaum, and Evans (1999). The variables used are industrial production, $Y$; the price level as measured by the consumer price index, $C P I$; the Journal of Commerce commodity price index, $C P$; the effective federal funds rate, $F F$; nonborrowed reserves, $N B R$; total reserves, $T R$; and the broad monetary aggregate, $M 2$. With the exception of $C P$ and $N B R$, the variables are identical to those used by Christiano, Eichenbaum, and Evans (1999). All of the variables except the funds rate are in natural logs. The data are monthly for the period 1959:01 to 2001:07. Following Christiano, Eichenbaum, and Evans (1999), the lag order is 12.13

Christiano, Eichenbaum, and Evans employ the Choleski factorization with the ordering $\{Y, P, C P$, $F F, N B R, T R, M 2\}$. Our analysis suggests, however, that if $F F$ is an EMV, it should come last in the

\footnotetext{
11 Applying the EMH only to financial prices is at odds with some recent New Keynesian literature. Some of the models in this literature employ forward-looking relations for output (and inflation) that resemble asset-pricing conditions (e.g., Estrella and Fuhrer, 2002). Of course, extending our analysis to such variables would make the identification problems discussed here even more severe because EMH-type behavior might be expected of other variables in the VAR besides financial prices or interest rates.

12 If the above argument applies, it applies primarily to the federal funds rate and then only over periods when the Fed explicitly targeted the funds rate. Moreover, Sims (1998) found that the qualitative results were unaffected by using either the Fed's discount rate or the commercial paper rate. We confirmed his finding; however, these results are not reported. The impulse response functions obtained using the federal funds rate were very similar to those obtained using a variety of other short-term rates.

${ }^{13}$ Qualitatively and quantitatively similar results are obtained with shorter lag lengths.
} 


\section{Figure 1}

\section{Impulse Response Functions for $Y$ with FF Fourth and Last in the} Cholesky Ordering

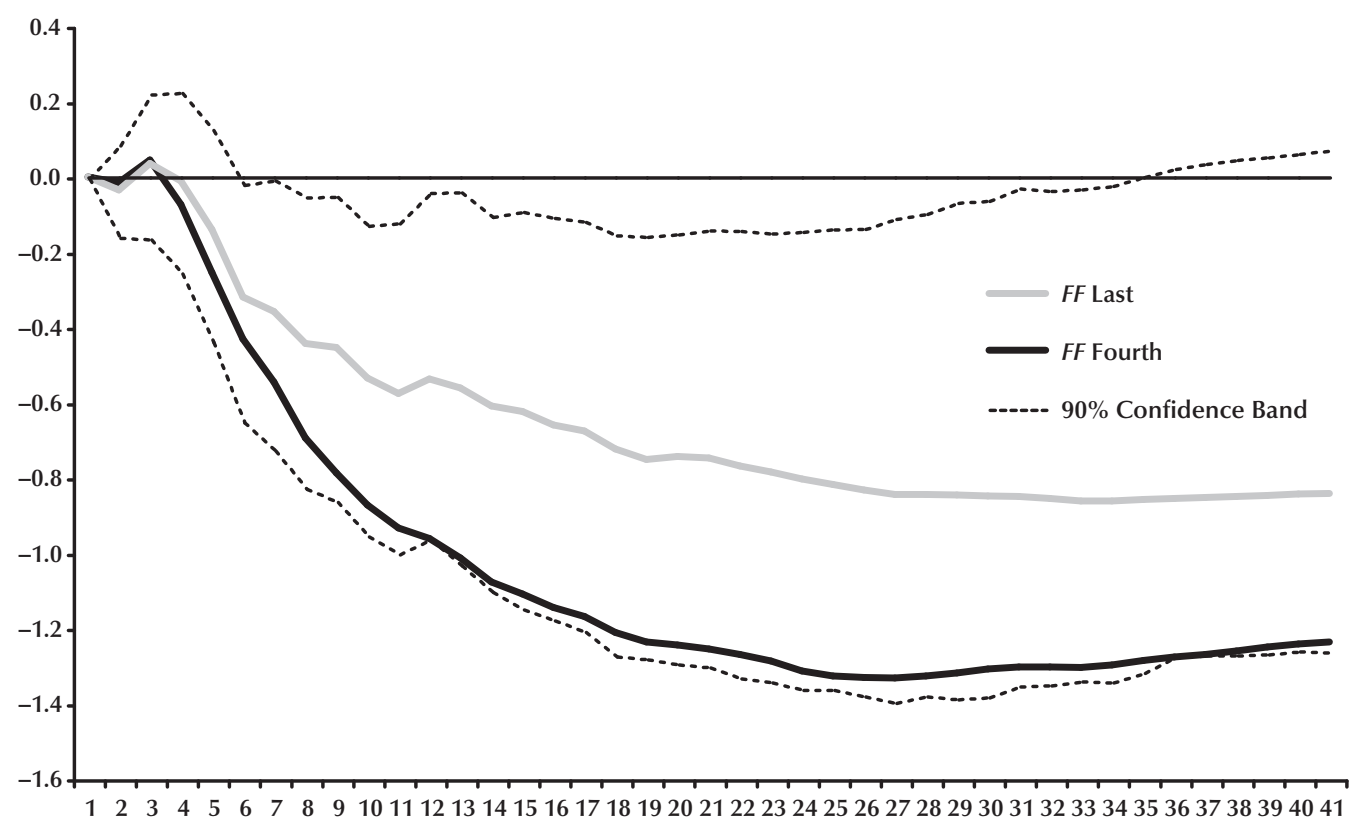

\section{Figure 2}

Impulse Response Functions for CPI with FF Fourth and Last in the Cholesky Ordering

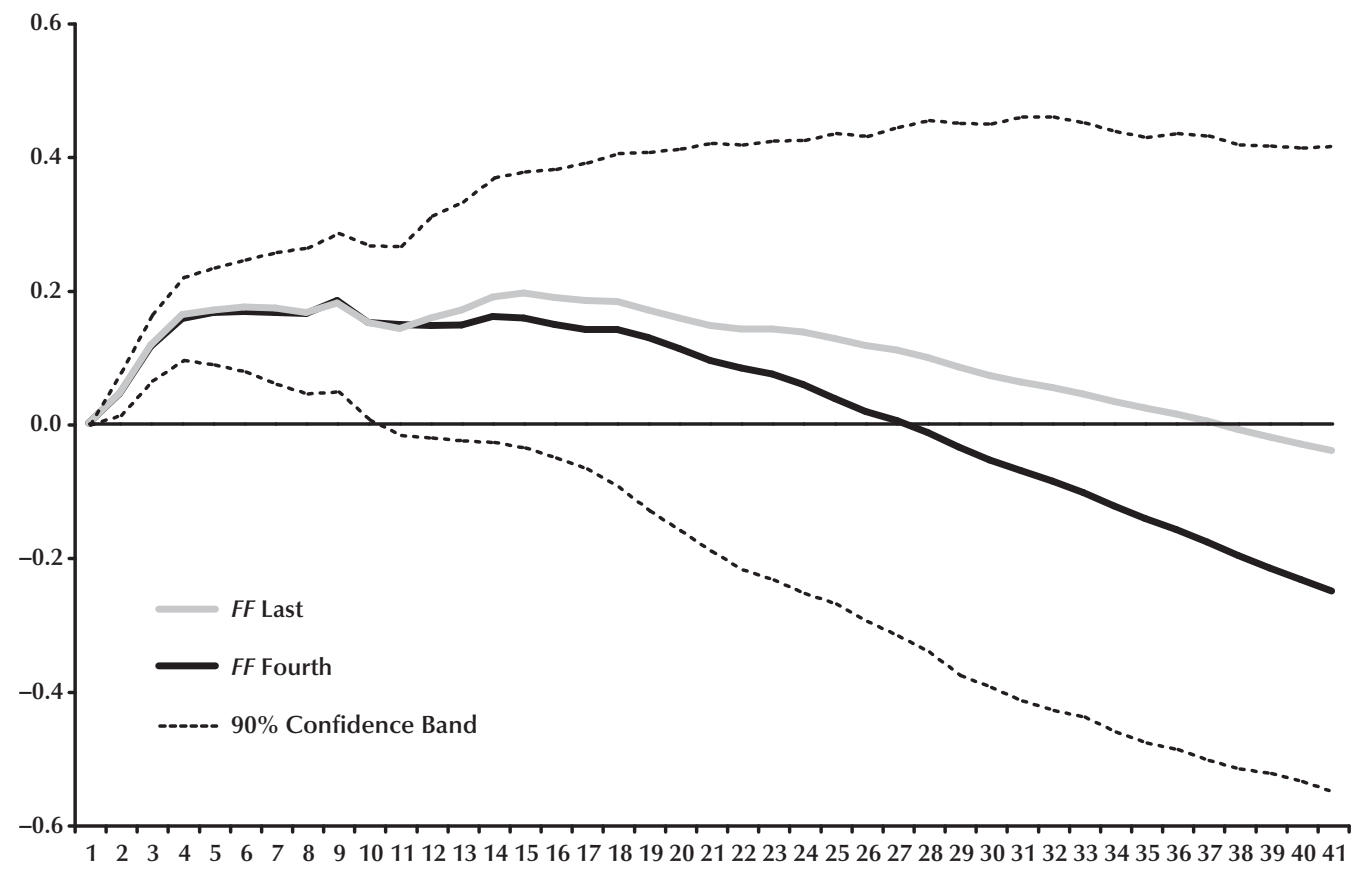




\section{Figure 3}

Impulse Response Functions for $C P$ with $F F$ Fourth and Last in the Cholesky Ordering

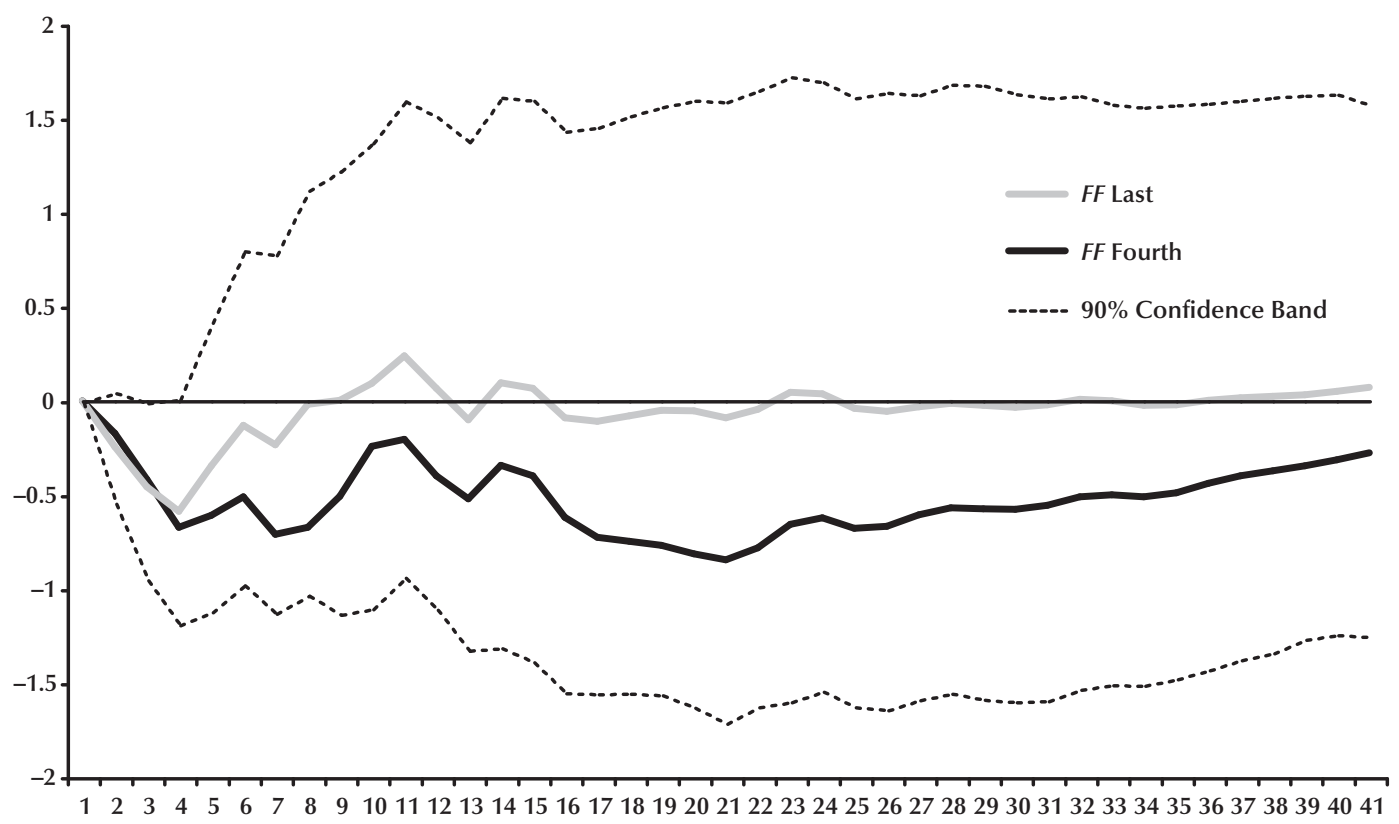

\section{Figure 4}

Impulse Response Functions for NBR with FF Fourth and Last in the Cholesky Ordering

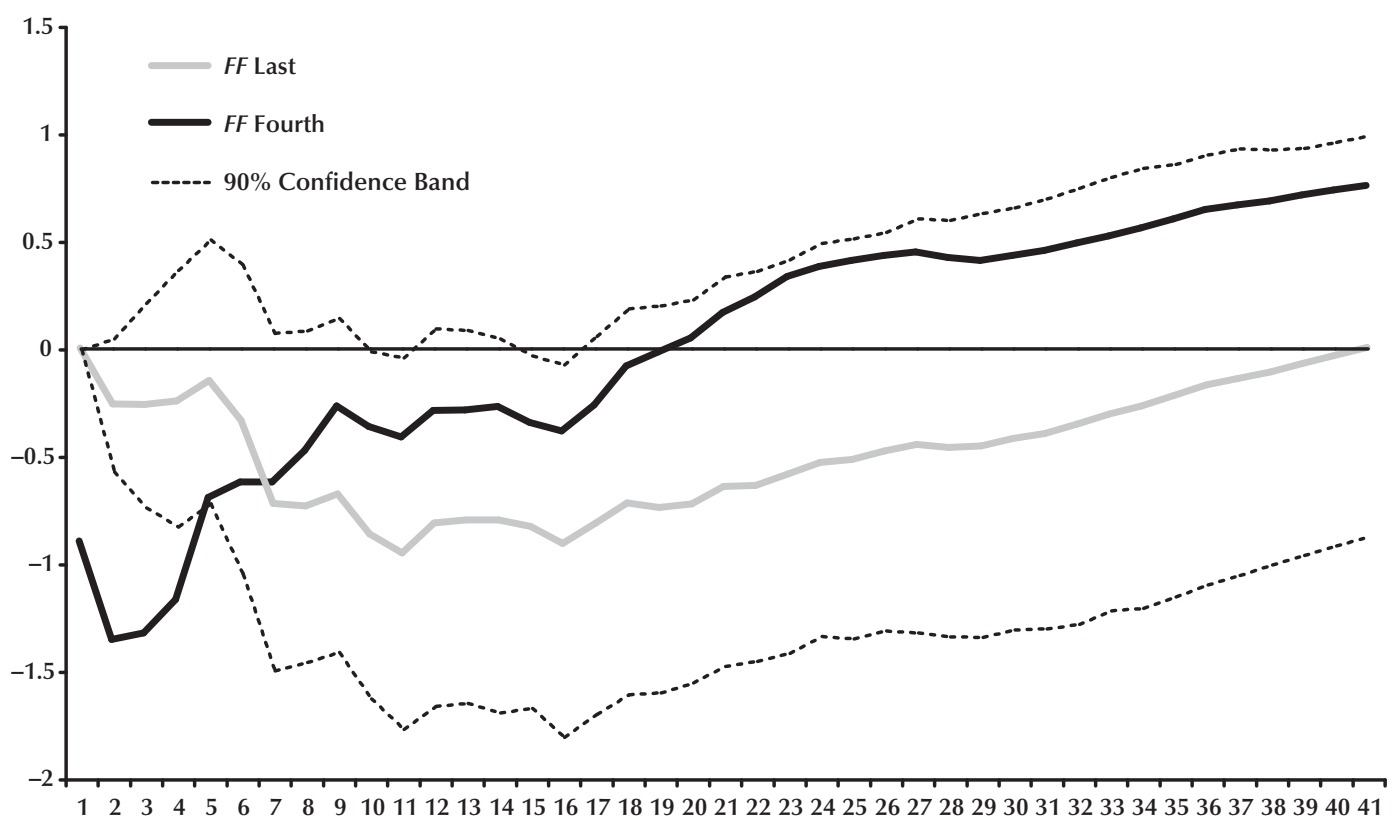




\section{Figure 5}

Impulse Response Functions for TR with FF Fourth and Last in the Cholesky Ordering

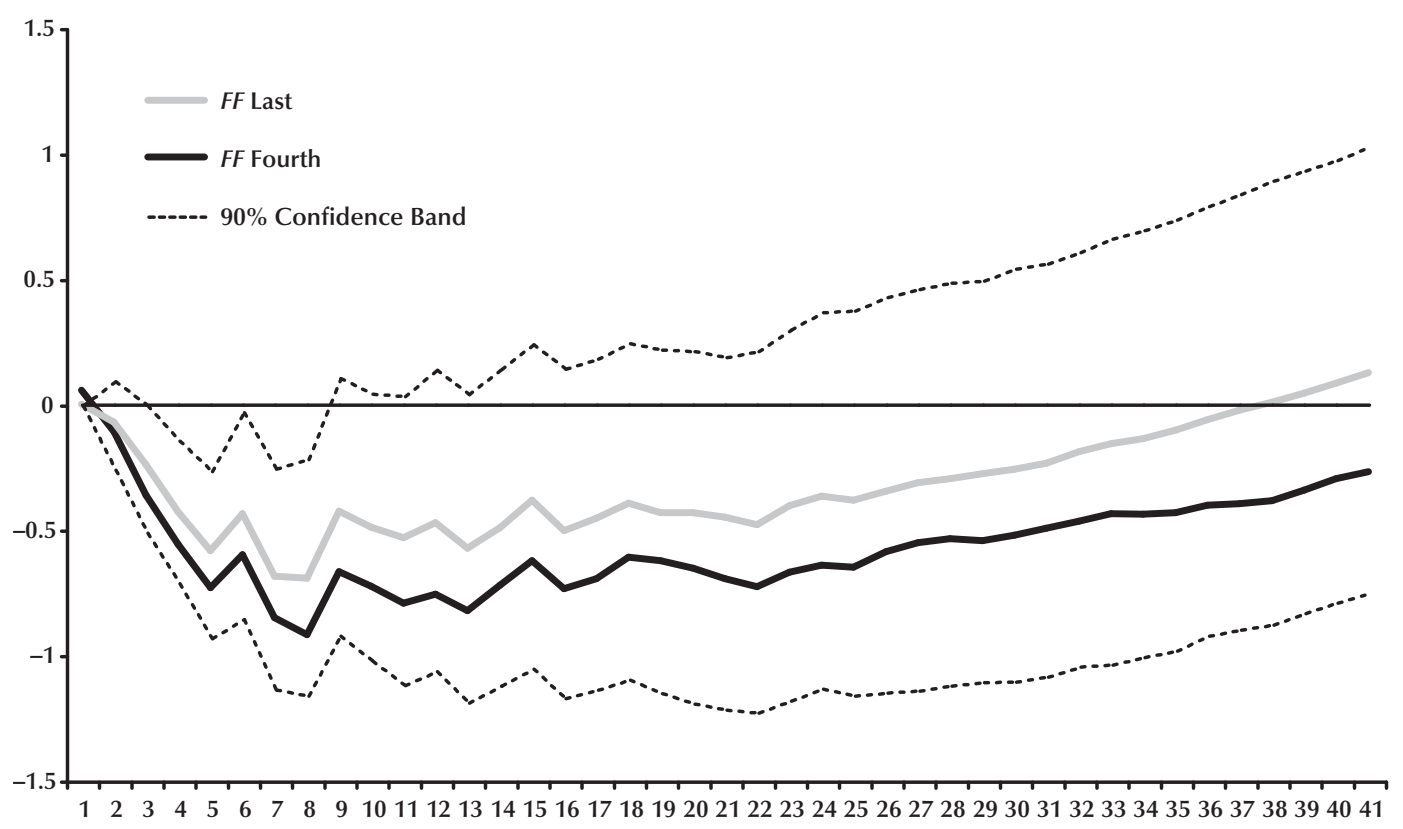

\section{Figure 6}

Impulse Response Functions for M2 with FF Fourth and Last in the Cholesky Ordering

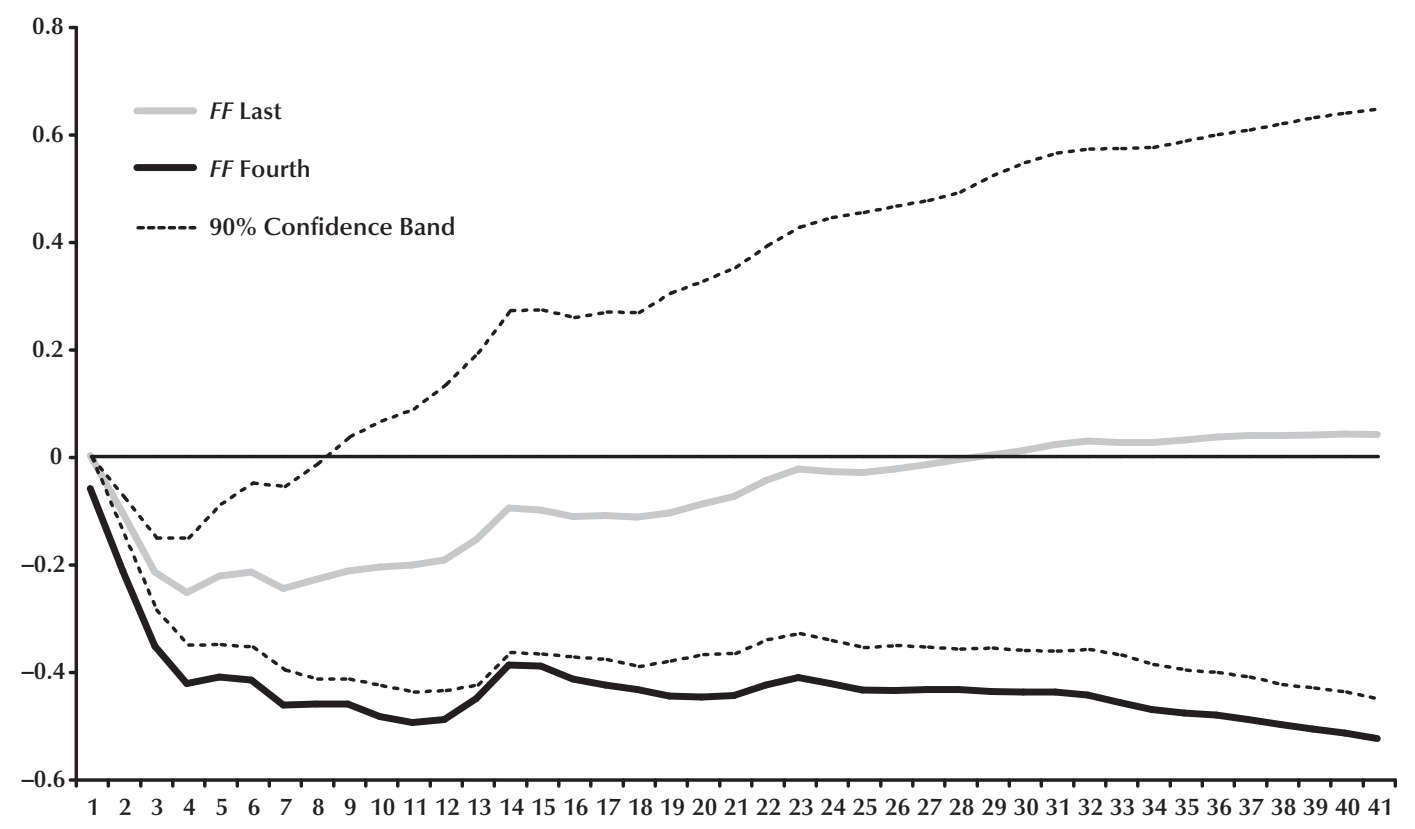




\section{Figure 7}

Impulse Response Functions for FF with FF Fourth and Last in the Cholesky Ordering

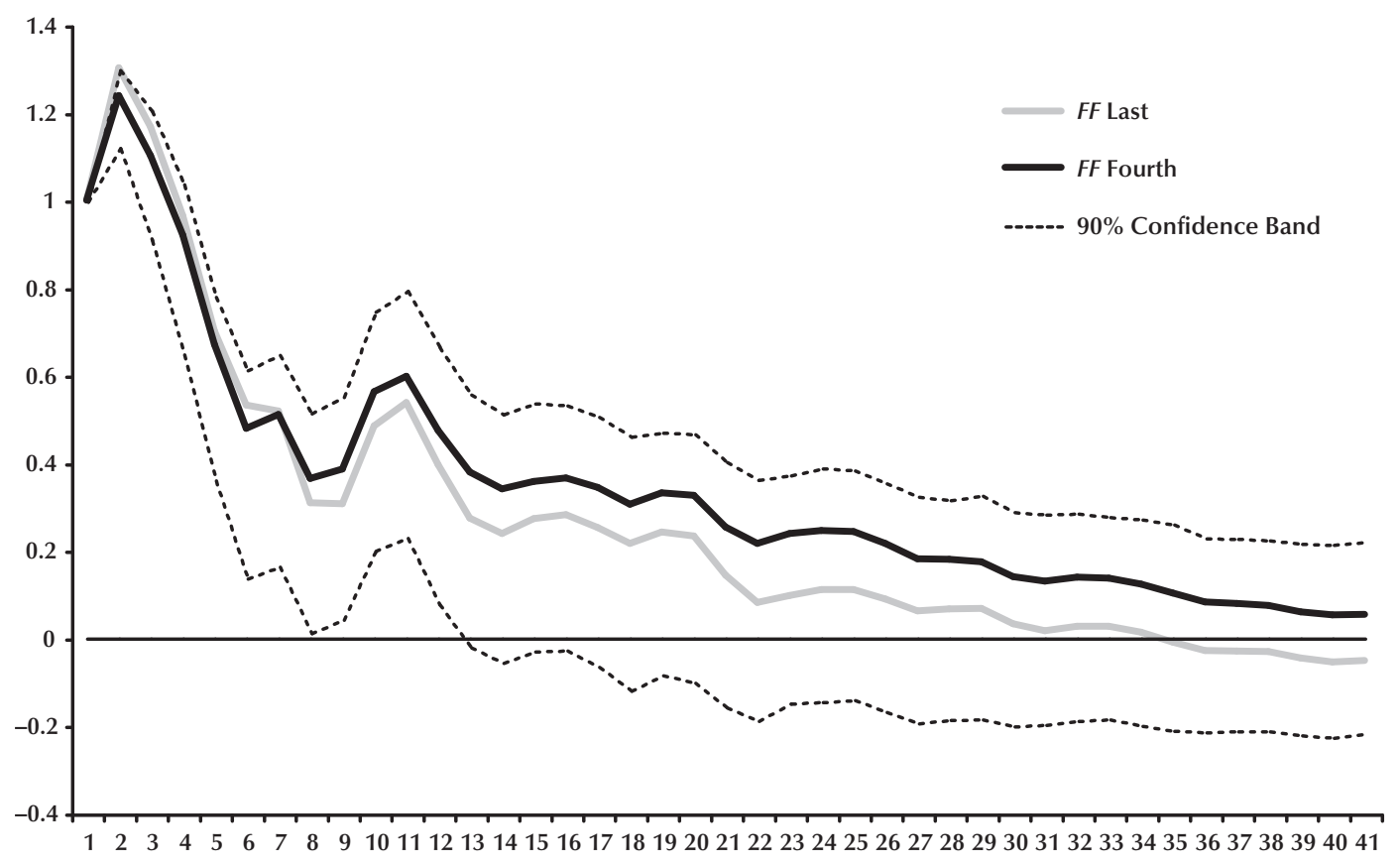

Choleski ordering. Hence, we compare the results with two orderings: $\{Y, P, C P, F F, N B R, T R, M 2\}$ and $\{Y, P, C P, N B R, T R, M 2, F F\}$.

Figures 1 through 7 show the impulse response functions of each of the variables to a one-unit shock to the funds rate when the funds rate is fourth in the ordering (the solid black line) and when the funds rate is last in the ordering (the solid gray line); they also show the 90 percent confidence interval (the dashed lines) for the impulse response functions obtained when FF comes last in the Choleski ordering. The confidence intervals are obtained by bootstrapping the model using 500 iterations. The effect of placing the funds rate in the middle rather than last in the recursive ordering is sometimes largeparticularly for a funds rate shock on output, where the effect with the funds rate in the middle drifts to the lower bound of the 90 percent confidence interval.

The effect is also large for NBR. This is not surprising because there is a strong and contemporaneous link between NBR and the funds rate (Pagan and Robertson, 1995; and Thornton, 2001). Thornton (2001) has shown that this relationship is due to the
Fed's operating procedure, which caused NBR to respond contemporaneously and endogenously to changes in the funds rate over much of this period. In any event, when the funds rate is last in the ordering, the contemporaneous relationship between the funds rate and $N B R$ is accounted for in the funds rate equation. With the contemporaneous relationship between the funds rate and NBR accounted for in the funds rate equation, shocks to the funds rate have no significant effect on NBR. Moreover, consistent with Thornton's (2001) analysis of the Fed's operating procedure, the effect of shocks to the funds rate on NBR and $T R$ is similar.

It is well known that the response to a shock may vary with the Choleski ordering. In this respect, these results are perhaps not surprising. We have provided a rationale for why the response is likely to change with the recursive ordering in some cases. Hence, these results raise doubts about the implications obtained from RSVARs. Note that while we obtained different results by placing the potential EMV last in the Choleski ordering, we are not advocating this as a "solution" to the problem of identification when RSVARs contain a potential EMV. We are only suggesting that these results are consistent 
with our overall conclusion that special care should be taken when identifying SVARs that include an EMV.

Of course, if the VAR includes two or more financial market variables, such as interest rates, stock prices, or exchange rates, identification is even more complicated. ${ }^{14}$ Such variables may be efficient at least in the semi-strong form of the EMH and, hence, will quickly reflect publicly known information. For example, a policy or other announcement that affects interest rates is likely also to affect stock prices or exchange rates. Garfinkel and Thornton (1995), who investigated the relationship between the federal funds rate, the overnight repo rate, and the 3-month T-bill rate using weekly average and daily data, found that shocks to interest rates that cause a differential between the funds rate and other rates were quickly eliminated. They also found that the idiosyncratic shocks to interest rates, as they identify them, are not correlated with three measures of monetary policy actions, suggesting that monetary policy actions were quickly reflected in market interest rates, including the federal funds rate. Consistent with these results, Sarno and Thornton (2003) found that disturbances to the equilibrium between the daily funds rate and the 3-month T-bill rate dissipate very rapidly.

The problem is that if economic variables contemporaneously reflect the same information, structural identifying assumptions that impose the condition that shocks do not affect such variables contemporaneously will be violated. While the importance of this critique for applied work is an empirical question, the empirical analysis presented here supports the argument that covariance restrictions imposed in the SVAR literature may be inappropriate and that greater caution should be exercised in choosing the identifying restrictions in such models.

\section{SUMMARY AND CONCLUSIONS}

The SVAR methodology identification is frequently applied by imposing restrictions that prevent economic variables from responding contemporaneously to one or more structural shocks. This paper shows that such restrictions are not applicable if the variable is efficient in the strong form of the

\footnotetext{
${ }^{14}$ In an effort to estimate the effect of monetary policy actions-shocks to the federal funds rate - on the yield curve, Evans and Marshall (1998) estimate a number of SVARs that include the effective federal funds rate and a "long-term rate," with maturities ranging from one month to ten years. Evans and Marshall use three alternative identifying assumptions, including a Choleski ordering
}

EMH because EMVs, as we term them, respond to all information.

While, strictly speaking, our analysis applies only to variables that are efficient in the strong form of the $\mathrm{EMH}$, the longer the period of time over which the data are measured, the more likely it is that the variables that are efficient in the semi-strong or weak forms of the EMH will reflect information that was initially known only to relatively few market participants. Hence, our analysis is likely to have implications for empirical analyses that use variables that are efficient in the semi-strong or weak forms of the EMH, especially when data are measured at monthly and quarterly frequencies and for markets where public (as opposed to private) information is dominant.

We illustrate the potential importance of our analysis by estimating a RSVAR often used to identify the effects of monetary policy shocks on the economy. Our results suggest that some of the effects of monetary policy shocks, so identified, are sensitive to whether the interest rate is ordered in the middle of the VAR, as is most often the case, or at the end (which avoids the problem in RSVARs that include only one EMV). This does not imply that one can simply overcome the problem by putting the EMV last in the Choleski ordering. It does, however, support our conclusion that researchers need to be extremely careful when using the standard contemporaneous identifying restrictions employed in the SVAR methodology when the VAR includes one or more variables that may satisfy some form of the EMH. Caution is particularly required when the data employed are at the monthly or quarterly frequency, as is often the case in applied macroeconomics and monetary economics.

\section{REFERENCES}

Bernanke, Ben S. "Alternative Explanations of the MoneyIncome Correlation." Carnegie-Rochester Conference Series on Public Policy, Autumn 1986, 25(0), pp. 49-99.

Blanchard, Olivier Jean and Quah, Danny. "The Dynamic Effects of Aggregate Demand and Supply Disturbances." American Economic Review, September 1989, 79(4), pp. 655-73.

Blanchard, Olivier Jean and Watson, Mark W. "Are Business Cycles All Alike?" in Robert J. Gordon, ed., The American Business Cycle. Chicago: University of Chicago Press, 1986.

Campbell, John Y.; Lo, Andrew W. and MacKinlay, A. Craig. 
The Econometrics of Financial Markets. Princeton: Princeton University Press, 1997.

Chordia, Tarun; Roll, Richard and Subrahmanyam, Avanidhar. "Evidence on the Speed of Convergence to Market Efficiency.” Unpublished manuscript, 2002.

Christiano, Lawrence J.; Eichenbaum, Martin and Evans, Charles L. "The Effects of Monetary Policy Shocks: Evidence from the Flow of Funds." Review of Economics and Statistics, February 1996, 78(1), pp. 16-34.

Christiano, Lawrence J.; Eichenbaum, Martin and Evans, Charles L. "Monetary Policy Shocks: What Have We Learned and To What End?" in John B. Taylor and Michael Woodford, eds., Handbook of Macroeconomics. Volume 1A. New York: Elsevier Science/North-Holland, 1999, pp. 65148 .

Clarida, Richard H.; Gali, Jordi and Gertler, Mark. "Monetary Policy Rules and Macroeconomic Stability: Evidence and Some Theory." Quarterly Journal of Economics, February 2000, 115(1), pp. 147-80.

Cooley, Thomas F. and LeRoy, Stephen F. "Atheoretical Macroeconomics: A Critique." Journal of Monetary Economics, November 1985, 16(3), pp. 283-308.

Cornell, Bradford. "Money Supply Announcements, Interest Rates, and Foreign Exchange." Journal of International Money and Finance, August 1982, 1(0), pp. 201-08.

Cornell, Bradford. "The Money Supply Announcement Puzzle: Review and Interpretation." American Economic Review, September 1983, 73(4), pp. 644-57.

Estrella, Arturo and Fuhrer, Jeffrey C. "Dynamic Inconsistencies: Counterfactual Implications of a Class of Rational-Expectations Models." American Economic Review, September 2002, 92(4), pp. 1013-28.

Evans, Charles L. and Marshall, David A. "Monetary Policy and the Term Structure of Nominal Interest Rates: Evidence and Theory." Carnegie-Rochester Conference Series on Public Policy, December 1998, 49(0), pp. 53-111.

Fleming, Michael J. and Remolona, Eli M. "What Moves the Bond Market?" Federal Reserve Bank of New York Economic Policy Review, December 1997, 3(4), pp. 31-50.

Fleming, Michael J. and Remolona, Eli M. "Price Formation and Liquidity in the U.S. Treasury Market: The Response to Public Information.” Journal of Finance, October 1999 , 54(5), pp. 1901 15.

Garfinkel, Michelle R. and Thornton, Daniel L. "The Information Content of the Federal Funds Rate: Is It Unique?" Journal of Money, Credit, and Banking, August 1995, 27(3), pp. 838-47.

Keating, John W. "Structural Approaches to Vector Autoregressions.” Federal Reserve Bank of St. Louis Review, September/October 1992, 74(5), pp. 37-57.

Klein, Lawrence R. Economic Fluctuations in the United States, 1921-1941. New York: Wiley and Sons, 1950.

Koopmans, Tjalling C. "Identification Problems in Economic Model Construction.” Econometrica, April 1949, 17(2), pp. 125-44.

Malkiel, Burton G. "Efficient Market Hypothesis," in Peter Newman, Murray Milgate, and John Eatwell, eds., The New Palgrave Dictionary of Money \& Finance. New York: MacMillan Press, 1992, pp. 739-44.

Pagan, Adrian R. and Robertson, John C. "Resolving the Liquidity Effect." Federal Reserve Bank of St. Louis Review, May/June 1995, 77(3), pp. 33-54.

Pesaran, M. Hashem. "Identification of Rational Expectations Models." Journal of Econometrics, August 1981, 16(3), pp. 375-98.

Roley, V. Vance and Walsh, Carl E. "Monetary Policy Regimes, Expected Inflation and the Response of Interest Rates to Money Announcements." Quarterly Journal of Economics, Supplement 1985, 100(4), pp. 1011-39.

Samuelson, Paul. "Proof that Properly Anticipated Prices Fluctuate Randomly." Industrial Management Review, 1965, 6, pp. 41-49.

Sarno, Lucio and Thornton, Daniel L. "The Dynamic Relationship Between the Federal Funds Rate and the Treasury Bill Rate: An Empirical Investigation.” Journal of Banking and Finance, June 2003, 27(6), pp. 1079-110.

Shapiro, Matthew D. and Watson, Mark W. "Sources of Business Cycle Fluctuations," in Stanley Fischer, ed., NBER Macroeconomic Annual 1988. Cambridge, MA: MIT Press, 1988, pp. 111-48. 
Sims, Christopher A. "Macroeconomics and Reality." Econometrica, January 1980, 48(1), pp. 1-48.

Sims, Christopher A. "Are Forecasting Models Usable for Policy Analysis?” Federal Reserve Bank of Minneapolis Quarterly Review, Winter 1986, 10(1), pp. 2-16.

Sims, Christopher A. "The Role of Interest Rate Policy in the Generation and Propagation of Business Cycles: What Has Changed Since the '30s?" in Jeffery Fuhrer and Scott Schuh, eds., Beyond Shocks: What Causes Business Cycles? Conference Series No. 42, Federal Reserve Bank of Boston, 1998, pp. 121-60.

Stock, James H. and Watson, Mark W. "Vector Autoregressions.” Journal of Economic Perspectives, Fall 2001, 15(4), pp. 101-15.

Schwert, G. William. "Anomalies and Market Efficiency." NBER Working Paper No. w9277, National Bureau of Economic Research, October 2002.

Thornton, Daniel L. “The Federal Reserve's Operating Procedure, Nonborrowed Reserves, Borrowed Reserves and the Liquidity Effect." Journal of Banking and Finance, September 2001, 25(9), pp. 1717-39.

Thornton, Daniel L. "The Effect of Unanticipated Money on the Money and Foreign Exchange Markets." Journal of International Money and Finance, December 1989, 8(4), pp. 573-87.

Wallis, Kenneth F. "Econometric Implications of the Rational Expectations Hypothesis." Econometrica, January 1980, 48(1), pp. 49-74.

Wold, H. "Causality and Econometrics." Econometrica, April 1954, 22(2), pp. 162-77. 